ORIGINAL ARTICLE

\title{
Influence of personality and emotional competences on academic performance: direct and indirect pathways mediated by perceived stress
}

\author{
Min You (D) $1 \cdot A, B, C, D, E, F$, Sylvain Laborde (D) $2,3 \cdot A, C, D, E, F$, Robert Samuel Vaughan (D) ${ }^{4 \cdot E, F}$, \\ Agnès Salinas ${ }^{1 \cdot E, F}$ \\ 1: Department of Psychology, EA 3918 CERREV, University of Caen Normandy, Caen, France \\ 2: Department of Performance Psychology, Institute of Psychology, German Sport University Cologne, Cologne, Germany \\ 3: EA 4260 CesamS, University of Caen Normandy, Caen, France \\ 4: School of Psychological and Social Sciences, York Saint John University, York, United Kingdom
}

\section{BACKGROUND}

Among the factors influencing academic performance (AP), individual differences at the trait level such as personality and emotional competences (EC) have been found to play a critical role, similarly to state variables such as perceived stress (PS).

PARTICIPANTS AND PROCEDURE

The aim of this study was to clarify whether the influence of personality (Big Five) and EC on AP (general point average) is direct and/or mediated via PS. 537 undergraduate students from a French university (112 male and 425 female, $M_{\text {age }}=19.84$ years, $S D_{\text {age }}=1.74$ years, range $=18-30$ years; first year: $n=293,55 \%$; second year: $n=162,30 \%$, third year: $n=82,15 \%)$ filled out the test battery around three weeks before the final examination.

\section{RESULTS}

Path analysis showed that AP was directly predicted by conscientiousness (+), neuroticism (+), extraversion $(-)$ and perceived stress $(-)$, while perceived stress was predicted by neuroticism (+) and by intrapersonal EC (-).

\section{CONCLUSIONS}

The results illustrate the robust influence of conscientiousness on AP, while EC was not found to influence AP directly, but indirectly via its effect on PS.

\section{KEY WORDS}

GPA; emotional intelligence; academic success; Big 5; university student

Corresponding author - Sylvain Laborde, Ph.D., Department of Performance Psychology, Institute of Psychology,

German Sport University Cologne, Am Sportpark Müngersdorf 6, 50937 Cologne, Germany,

e-mail: s.laborde@dshs-koeln.de

AUthors' CONTRIBUtion - A: Study design - B: Data collection - C: Statistical analysis - D: Data interpretation .

E: Manuscript preparation · F: Literature search · G: Funds collection

TO CITE THIS ARTICLE - You, M., Laborde, S., Vaughan, R. S., \& Salinas, A. (2022). Influence of personality and emotional competences on academic performance: direct and indirect pathways mediated by perceived stress. Current Issues

in Personality Psychology, 10(1), 61-70.

RECEIVED 19.03.2021 · REVIEWED 06.10.2021 · ACCEPTED 09.11.2021 · PUBLISHED 12.12.2021 


\section{BACKGROUND}

Understanding the predictors of academic performance is of utmost interest for educational researchers, teachers, and of course for students themselves (Droppert et al., 2019; Kim et al., 2017; Stajkovic et al., 2018). Academic performance can be influenced by factors beyond intelligence such as meta-cognitions (Ohtani \& Hisasaka, 2018), health (Shaw et al., 2015), class attendance and social support (Kassarnig et al., 2018), behavioral and emotional characteristics (Park et al., 2019), and also by personality traits, e.g., the Big Five (McCrae \& Costa, 2008), and emotional dispositions (e.g., Saklofske et al., 2012). The current study focuses on the latter. We aim to clarify whether the influence of the Big Five and emotional competences (EC) on academic performance is direct, or mediated via a state affective variable, perceived stress.

Perceived stress reflects an appraisal of the situation where demands tax or overcome resources (Lazarus \& Folkman, 1984). University students usually perceive academic life to be stressful and demanding (Hammer et al., 2010; Kausar, 2010; Wan et al., 1992). Specifically, they report experiencing a range of emotional and cognitive reactions to this perceived stress, in particular due to external pressures and self-imposed expectations, involving adjusting to both academic and social demands (Misra \& McKean, 2000). In students, perceived stress was found to be negatively associated with academic performance (Duchesne \& Larose, 2018; Frazier et al., 2019; Gustems-Carnicer et al., 2019). Among students, perceived stress is also negatively associated with performance-related factors such as coping selfefficacy, resilience, and social support (Frazier et al., 2019). Students perceiving less stress use less avoidant-coping strategies and more problem-focused coping strategies (Gustems-Carnicer et al., 2019). Understanding how individual differences affect perceived stress and appraisal is therefore relevant to understanding how to deal with it (Kilby et al., 2018). In an academic context (Saklofske et al., 2012), the five subcomponents (self-perception, interpersonal, decision making, self-expression, and stress management) measured with the Emotional Quotient Inventory (Bar-On, 2002) were found to be negatively related to perceived stress, while for the Big Five, extraversion, agreeableness, and conscientiousness were found to be negatively related, and neuroticism positively related. However, whether perceived stress mediates the relationship between individual differences and academic performance has not yet been examined; thus we aim to address this gap.

According to meta-analyses, the Big Five has been consistently found to be related to academic performance (Poropat, 2009; Stajkovic et al., 2018; Vedel, 2014). Specifically, a positive association was reported between grade point average and agreeableness, and openness, with the strongest relationship found with conscientiousness. Conscientious students usually show greater motivation and effort toward their studies (Chamorro-Premuzic \& Furnham, 2014; De Raad \& Schouwenburg, 1996). Neuroticism and extraversion seem to be less connected with academic achievement, and hypotheses about potential connections are rather ambiguous (Tetzner et al., 2020). Among the Big Five traits, neuroticism may be most relevant when considering potential mediation via perceived stress, while the other traits may be mediated by other mechanisms. Neuroticism is expected to increase perceived stress in students due to focusing on negative affectivity (Schmidt et al., 2013), which may in turn negatively influence academic performance.

EC refer to how individuals differ in the way they identify, express, understand, regulate, and use their own (i.e., intrapersonal) and others' (i.e., interpersonal) emotions (Brasseur et al., 2013). They are assessed with self-report measures such as the profile of emotional competences (PEC; Brasseur et al., 2013). The theory of EC builds on emotional intelligence (EI) research, but uses the concept of competences, given that competences contrary to intelligence can be taught and learned. The current study is, to our knowledge, the first based on the theory of EC using the PEC to investigate its relationship with academic performance. To date, previous research has shown that trait EI was related positively to academic performance, as found in a meta-analysis (Perera \& DiGiacomo, 2013). Several pathways have been suggested to explain this relationship (Perera, 2016), specifically its association with perceived stress (Laborde et al., 2010; Watson \& Watson, 2016).

Regarding the respective influence of the Big Five and EC on academic performance, previous research showed that trait EI, measured via self-report (Di Fabio \& Palazzeschi, 2009, 2015; Downey et al., 2013; Mancini et al., 2017; Saklofske et al., 2012; Siegling et al., 2015), and ability EI, measured with performance tests (Di Fabio \& Palazzeschi, 2009), usually predict additional academic performance variance beyond the Big Five. Trait EI was also found to predict academic motivation beyond the Big Five (Siegling et al., 2015). Some contrary evidence exists as well; for example, academic performance was predicted by conscientiousness and openness positively, and neuroticism negatively, while only one of the EI subcomponents (adaptability) was found to be related to academic performance, with a small effect size (Saklofske et al., 2012). Two drawbacks can be identified in this line of research: First, so far, differences between intrapersonal and interpersonal $\mathrm{EC}$ in the way they influence academic performance have received little attention (for an exception see Saklofske et al., 2012), while this may help to better understand how EC may be related to academic 
performance. Second, potential mediators were not taken into account, and we focus in this research on perceived stress.

To sum up, this study aims to clarify the pathways linking the Big Five and EC to academic performance, and to clarify whether some of these relationships may be mediated via perceived stress. Using path analysis and based on theory and on previous research findings, we hypothesize that for the Big Five and academic performance, direct positive relationships with conscientiousness, agreeableness, and openness will be found (Poropat, 2009; Vedel, 2014), while no direct relationships are expected with neuroticism and extraversion. In addition, we predicted that neuroticism will have an influence on academic performance via perceived stress (Schmidt et al., 2013; Tetzner et al., 2020). Regarding intrapersonal and interpersonal EC, we hypothesize both a direct pathway to academic performance and an indirect pathway mediated via perceived stress (Brasseur et al., 2013; Di Fabio \& Palazzeschi, 2009, 2015; Downey et al., 2013; Mancini et al., 2017).

\section{PARTICIPANTS AND PROCEDURE}

\section{PARTICIPANTS}

Five hundred thirty-seven undergraduate psychology students from a French university (112 male and 425 female, $M_{\text {age }}=19.84$ years, $S D_{\text {age }}=1.74$ years, range $=18$-30 years; first year: $n=293,55 \%$, second year: $n=162,30 \%$, third year: $n=82,15 \%$ ) participated in the study and gave permission for their exam results to be retrieved at the end of the academic year. In order to determine mediation effects with bias-corrected bootstrapping, Fritz and Mackinnon (2007) recommend a minimum sample of 400 participants for medium indirect effects. The study was approved by the Ethics Committee of the University of Caen Normandy (no. 07/2017).

\section{MEASURES}

The Profile of Emotional Competences (PEC; Brasseur et al., 2013). The PEC comprises 50 items and encompasses 10 subscales (intrapersonal identification, intrapersonal expression, intrapersonal comprehension, intrapersonal regulation, intrapersonal utilization, interpersonal identification, interpersonal expression, interpersonal comprehension, interpersonal regulation and interpersonal utilization) of 5 items each, grouped into two factors (intrapersonal EC and interpersonal EC) and one global EC score. Each item consists of a short statement, to which participants are asked to indicate how closely they identify using a five-point scale, from 1 (the proposal does not fit you at all or you never react in this way) to 5 (you recognize yourself completely in what is described or it happens to you very often). Sample items are: "I use my feelings to improve my choices in life" or "I feel uncomfortable if people tell me about their problems, so I try to avoid it".

Big-Five Inventory (Plaisant et al., 2010). The French version of the Big Five Inventory (Plaisant et al., 2010) is a 45-item self-reported scale, reflecting the five main dimensions: extraversion, conscientiousness, openness, agreeableness, and neuroticism. The Big Five Inventory French version (BFI-Fr) does not use single adjectives as items because such items are answered less consistently than when they are accompanied by definitions or elaboration. It uses 45 short phrases based on the trait adjectives known to be prototypical markers of the Big Five. Each item consists of a short statement beginning with "I see myself as someone who..., to which participants are asked to indicate how closely they identify using a five-point scale, from 1 (strongly disagree) to 5 (strongly agree). Sample items are: "Tends to be lazy" or "Can be somewhat careless".

Perceived Stress Scale (PSS; Bellinghausen et al., 2009). Compared to the original 14-item scale (Cohen et al., 1983), this 10-item version of the French adaptation is validated within the French working population. The scale comprises two distinct factors: perceived work overload and perceived personal efficacy. Each item consists of a short statement, to which participants are asked to indicate how often they felt or thought a certain way by using a five-point scale, from 1 (never) to 5 (very often). Sample items are: "In the last month, how often have you felt that things were going your way?" or "In the last month, how often have you felt nervous and stressed?"

\section{PROCEDURE}

A convenience sampling procedure was used in 2018. The students participated in the study during class settings around three weeks before the end of year examination. The survey included the instruments listed above, a set of demographic questions, and a section where students could give their student ID number and allow this to be used to retrieve their final result (grade point average) at the end of the academic year. Students also gave their permission for their end-of-the-year grade to be accessed. The grade point average was based on a scale from 0 to 20 , and corresponds to the average of exam results related to a certain number of subjects (see Table 1 for the details of the subjects). For the first and second academic year, there were 8 exams counting each for 6 ECTS (European Credit Transfer and Accumulation System), and 6 exams counting for 2 ECTS each. In the third academic year, there were 10 exams counting 
for 6 ECTS each. The full description of subjects can be seen in Table 1 . The full test battery took around 20 minutes to complete. Students were informed that participation in the study was voluntary, and that they could withdraw their participation in the study at any point without giving explanations, and without consequences.

\section{DATA ANALYSIS}

First zero-order Pearson correlations were computed. Then we tested the hypothesized model via path analysis with the software AMOS 22.0 (see Figure 1). Goodness of fit was assessed with the $\chi^{2}$ index, the comparative fit index (CFI), the Tucker-Lewis index

\section{Table 1}

Details of the subjects for each academic year

\begin{tabular}{|c|c|c|c|}
\hline Year & Semester & Subject & ECTS \\
\hline \multirow[t]{10}{*}{ First year } & First semester & Foundations and Major Concepts of Psychology & 6 \\
\hline & & Perception \& Action & 6 \\
\hline & & Introduction to Clinical Psychology & 6 \\
\hline & & Pedagogy & 6 \\
\hline & & Basic Skills (English/Methods/Statistics) & 6 \\
\hline & Second semester & Developmental Psychology & 6 \\
\hline & & Social Psychology & 6 \\
\hline & & Interaction \& Communication & 6 \\
\hline & & Children Psychology & 6 \\
\hline & & Basic Skills (English/Methods/Statistics) & 6 \\
\hline \multirow[t]{10}{*}{ Second year } & Third semester & Intelligence and Learning & 6 \\
\hline & & Clinical Psychology: Psychodynamical Approaches & 6 \\
\hline & & Memory and Amnesia & 6 \\
\hline & & Language & 6 \\
\hline & & Basic Skills (English/Methods/Statistics) & 6 \\
\hline & Fourth semester & Relationships and Interactions & 6 \\
\hline & & Attention \& Executive Functions & 6 \\
\hline & & Emotions and Psychopathology & 6 \\
\hline & & Norms and Judgments & 6 \\
\hline & & Basic Skills (English/Methods/Statistics) & 6 \\
\hline \multirow[t]{10}{*}{ Third year } & Fifth semester & Neuroscience & 6 \\
\hline & & Social Psychology: Change/Discrimination & 6 \\
\hline & & Social Psychology: Neuropsychological Approach & 6 \\
\hline & & Methods - Psychological Therapy & 6 \\
\hline & & Basic Skills (English/Methods/Statistics) & 6 \\
\hline & Sixth semester & Developmental Psychology & 6 \\
\hline & & Psychoanalysis & 6 \\
\hline & & Reasoning, Learning and Education & 6 \\
\hline & & Methods (Psychological Practice) & 6 \\
\hline & & Introduction to Psychological Research & 6 \\
\hline
\end{tabular}

Note. ECTS - European Credit Transfer and Accumulation System. 
Figure 1

Hypothesized model concerning the relationship between the Big Five, the profile of emotional competences, academic performance, and perceived stress

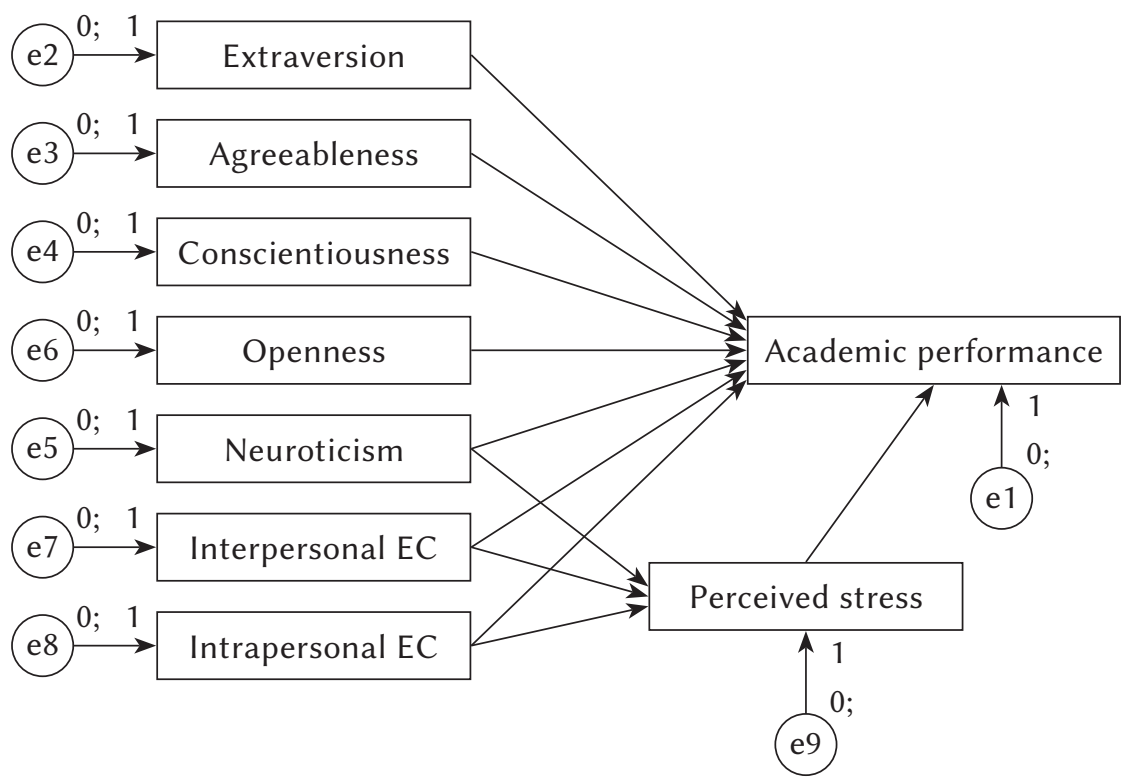

(TLI), the standardized root mean square residual (SRMR), and the root mean square error of approximation (RMSEA). Following recommendations (Hu \& Bentler, 1999), values below 0.08 for the SRMR and below 0.06 for the RMSEA show an acceptable fit. Regarding CFI and TLI, values higher than 0.95 indicate an acceptable model fit (Hu \& Bentler, 1999). In addition we provide the $\chi^{2}$ value as a subjective index of fit, with small values indicating a good fit (Jöreskog, 1993).

\section{RESULTS}

All variables indicated acceptable internal consistency scores. Full descriptive statistics and zero order correlations can be seen in Table 1. Zero-order correlations indicated that four variables were significantly related to academic performance: conscientiousness $(r=.34, p<.001)$, extraversion $(r=-.10$, $p=.020)$, neuroticism $(r=.12, p=.004)$, and perceived stress $(r=-.10, p=.020)$. No correlations were found with global EC, inter-EC or intra-EC and academic performance $(p>.05)$. However, they were correlated with perceived stress, for global EC $(r=-.37$, $p<.001)$, intra-EC $(r=-.48, p<.001)$, and inter-EC $(r=-.12, p=.006)$

The hypothesized model did not yield satisfactory fit. Based on estimates and suggested modification indices fitting our theoretical background, we adapted the hypothesized model (see Figure 2). The final model fit was $\chi^{2}(5)=19.54, \mathrm{CFI}=.98, \mathrm{TLI}=.93$, RMSEA $=.07$, $\mathrm{SRMR}=.04$. Path analysis showed that academic per- formance was directly predicted by (standardized estimates are provided): conscientiousness (.33), neuroticism (.21), extraversion (-.11) and perceived stress $(-.18)$, while perceived stress was predicted positively by neuroticism (.46) and negatively by intrapersonal emotional competences (-.24).

\section{DISCUSSION}

Our study aimed to investigate the direct influence of the Big Five traits and emotional competences on academic performance, as well as a potential mediation via perceived stress. Specifically, we hypothesized a direct pathway to academic performance for three of the Big Five traits (i.e., openness, agreeableness, and conscientiousness) as well as for intra- and interpersonal emotional competences, and an indirect pathway for neuroticism, as well as for intra- and interpersonal emotional competences via perceived stress. As our hypothesized model did not show a good fit to the data, we refined our model based on estimates and modification index analysis suggested by AMOS, in line with our theoretical background. The final model showed a direct positive pathway for academic performance with conscientiousness and neuroticism, and a direct negative pathway with extraversion and perceived stress. In addition, an indirect pathway was found with perceived stress, predicted positively by neuroticism and negatively by intrapersonal emotional competences.

The findings regarding the direct pathway between conscientiousness and academic performance 
Direct and indirect pathways mediated by perceived stress

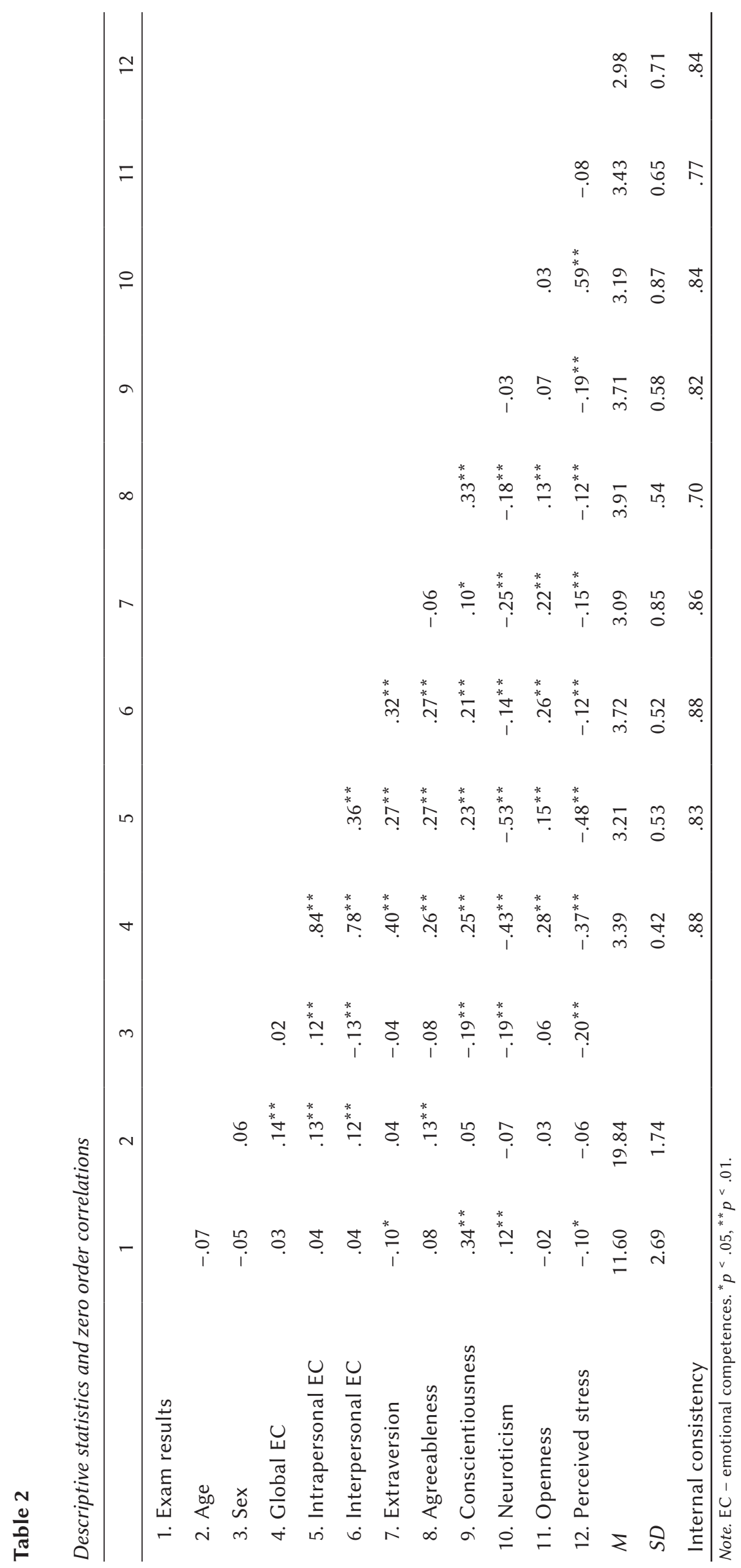


Figure 2

Final model with standardized factor loadings

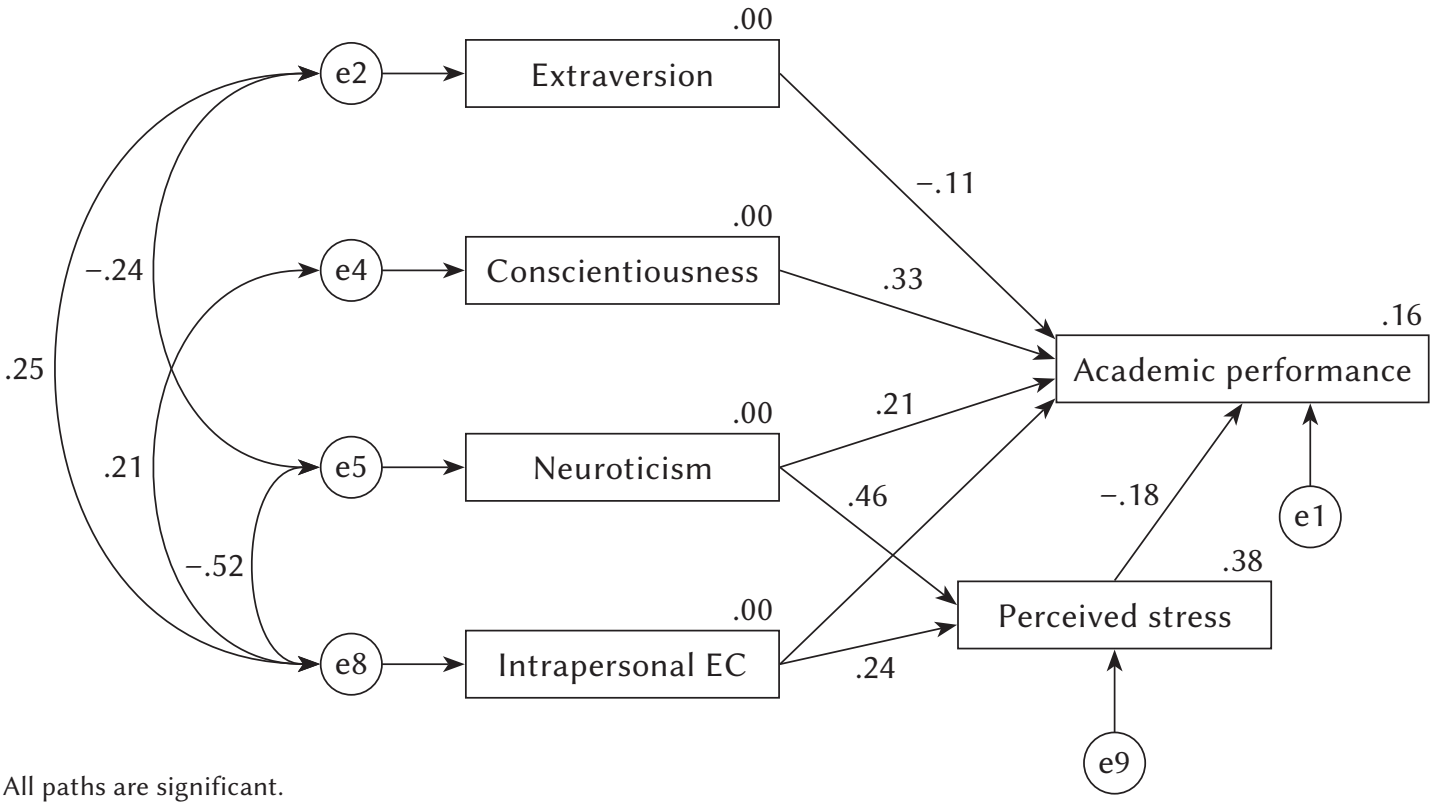

Note. All paths are significant.

are the most robust of the literature (Poropat, 2009; Stajkovic et al., 2018; Vedel, 2014). Regarding extraversion and neuroticism, their relationship with academic performance is considered as rather ambiguous (Tetzner et al., 2020). For extraversion, it may be that the negative relationship found here could be explained by the fact that extroverted students may be distracted by non-relevant academic tasks (Bidjerano $\&$ Dai, 2007). The positive relationship with neuroticism may be explained by the additional efforts put by students high in neuroticism into exam preparation in order to cope with a potential threatening event (Rosander et al., 2011). The fact that openness and agreeableness did not appear as predictors in our sample, contrary to what was found in previous meta-analyses (Poropat, 2009; Vedel, 2014), may be due to the fact that the characteristics of the end of year exams (e.g., mostly multiple choice questionnaires) did not rely on aspects related to openness such as curiosity (Gatzka \& Hell, 2018), or regarding agreeableness that cooperation with peers and teachers had little influence on exam results (Miller et al., 2003).

The negative relationship between perceived stress and academic performance is in line with previous research (Duchesne \& Larose, 2018; Frazier et al., 2019; Gustems-Carnicer et al., 2019). Pre-stress examination may be detrimental to academic performance in that it hinders learning and memory retrieval during the exam. Two traits were found to influence perceived stress, negatively with intrapersonal EC, and positively with neuroticism. Dealing optimally with one's own emotions may certainly help in reducing perceived stress, with the imple- mentation of effective coping strategies (Saklofske et al., 2012), while dealing with others' emotions was not found to have any influence here, which is potentially linked to the finding with agreeableness noted above. Regarding neuroticism, the focus on negative affectivity tends to increase perceived stress (Schmidt et al., 2013), potentially due to increased anxiety and negative cognitions (Gallagher, 1990). The case of neuroticism is interesting, given that it was found to have either a positive direct influence on academic performance or a negative influence when mediated via perceived stress, which speaks for the ambiguity of the relationship between neuroticism and academic performance, as pointed out in previous research (Tetzner et al., 2020).

Regarding the relationship between EC and academic performance, no direct relationship was found, contrary to previous research with EI (Di Fabio \& Palazzeschi, 2009, 2015; Downey et al., 2013; Mancini et al., 2017; Perera \& DiGiacomo, 2013). Our findings are rather similar to those of Saklofske et al. (2012), who found that academic performance was more associated with the Big Five traits than with EI. Future research is required to investigate whether the questionnaires used to assess EI/EC may play a role in the findings, given that they reflect different theoretical backgrounds (Laborde \& Allen, 2016). Also differentiating self-report (trait perspective) and performance measures (ability perspective) of EC may prove helpful, given the previous research showing that ability EI predicted academic performance more in comparison to trait EI (Di Fabio \& Palazzeschi, 2009).

The main limitation of our study is that we did not control for cognitive ability (Meyer et al., 2019; 
Ohtani \& Hisasaka, 2018) or previous academic performance (Thomas et al., 2017). Further, only psychology students of one university took part in this study, which makes it difficult to generalize the findings regarding academic performance. Additionally, we could not check the distribution of achievement for each separate subject constituting the grade point average. This issue should be investigated in future research, given that different emotion regulation factors will be involved in challenging (i.e., where few students achieve high grades) vs. less challenging exams (i.e., where most students achieve high grades). Finally, our design was cross-sectional, which does not allow a causal interpretation of the data.

\section{CONCLUSIONS}

Our study investigated the influence of the Big Five and EC on academic performance, and specifically whether the relationship with specific traits would be mediated via perceived stress. We found that academic performance was directly predicted by conscientiousness $(+)$, neuroticism $(+)$, extraversion $(-)$ and perceived stress $(-)$, while perceived stress was predicted by neuroticism (+) and by intrapersonal emotional competences $(-)$. Future research should clarify whether these results extend to other samples, and also to what extent the EI/EC assessment (choice of instrument: self-report vs. performance test) influences the results. These findings further our understanding about how individual differences may influence academic performance, and may therefore inform the development of interventions, identifying those students who may benefit most from a stress management intervention to prepare them for exams and future related outcomes.

At the practical level, the development of stress management interventions can be informed by the findings of a recent meta-analysis (Amanvermez et al., 2020) showing that stress management interventions for college students were particularly effective in reducing stress, depression, and anxiety, and specifically for students reporting high stress levels. Based on the categorization used in this metaanalysis, the stress management interventions may target the following aspects: cognitive-behavioral therapy with for example cognitive restructuring and stress inoculation; third-wave concepts ${ }^{1}$ focusing on acceptance, defusion, values, and mindfulness; mind-body interventions, including meditation, muscle relaxation, breathing exercises, guided imaginary techniques, and biofeedback, and finally skills training interventions focusing at improving social, academic, or coping skills. As we see, the range of potential stress interventions addressing students' needs is quite large. Although some of them could be potentially learned autonomously by the stu- dents themselves, we would strongly recommend educational institutions and universities to provide a dedicated support service to help students cope with stress, given the impact it has on their academic performance.

\section{ENDNOTE}

1 In short, first wave therapy refers to the first "wave" of scientifically based psychotherapy, and corresponds to behavioral therapy as developed in the 1950s, second wave therapy refers to cognitive behavioral therapy as developed in the 1970s, and third wave therapy is seen as an evolution of traditional cognitive behavioral therapy emphasizing contextual and experiential change strategies in addition to more direct and didactive ones (for a detailed discussion, see Ost, 2008).

\section{References}

Amanvermez, Y., Rahmadiana, M., Karyotaki, E., de Wit, L., Ebert, D. D., Kessler, R. C., \& Cuijpers, P. (2020). Stress management interventions for college students: a systematic review and metaanalysis. Clinical Psychology: Science and Practice. https://doi.org/10.1111/cpsp.12342

Bar-On, R. (2002). Bar-On Emotional Quotient Inventory: Short. Technical manual. Multi-Health Systems.

Bellinghausen, L., Collange, J., Botella, M., Emery, J.-L., \& Albert, É. (2009). Validation factorielle de l'échelle française de stress perçu en milieu professionnel [Factorial validation of the French Scale for Perceived Stress in the Workplace]. Santé Publique, 21, 365-373. https://doi.org/10.3917/ spub.094.0365

Bidjerano, T., \& Dai, D. Y. (2007). The relationship between the Big-Five model of personality and selfregulated learning strategies. Learning and Individual Differences, 17, 69-81. https://doi.org/10.1016/j. lindif.2007.02.001

Brasseur, S., Grégoire, J., Bourdu, R., \& Mikolajczak, M. (2013). The Profile of Emotional Competence (PEC): Development and validation of a self-reported measure that fits dimensions of emotional competence theory. PLoS One, 8, 1-8. https://doi.org/10.1371/journal.pone.0062635

Chamorro-Premuzic, T., \& Furnham, A. (2014). Personality and intellectual competence. Taylor \& Francis.

Cohen, S., Kamarck, T., \& Mermelstein, R. (1983). A global measure of perceived stress. Journal of Health and Social Behavior, 24, 385-396. https://doi. org $/ 10.2307 / 2136404$

De Raad, B., \& Schouwenburg, H. C. (1996). Personality in learning and education: a review. European Journal of Personality, 10, 303-336. https://doi. 
org/10.1002/(sici)1099-0984(199612)10:5<303::aidper262>3.0.co;2-2

Di Fabio, A., \& Palazzeschi, L. (2009). An in-depth look at scholastic success: Fluid intelligence, personality traits or emotional intelligence? Personality and Individual Differences, 46, 581-585. https:// doi.org/10.1016/j.paid.2008.12.012

Di Fabio, A., \& Palazzeschi, L. (2015). Beyond fluid intelligence and personality traits in scholastic success: Trait emotional intelligence. Learning and Individual Differences, 40, 121-126. https://doi. org/10.1016/j.lindif.2015.04.001

Downey, L. A., Lomas, J., Billings, C., Hansen, K., \& Stough, C. (2013). Scholastic success. Canadian Journal of School Psychology, 29, 40-53. https://doi. org/10.1177/0829573513505411

Droppert, K., Downey, L., Lomas, J., Bunnett, E. R., Simmons, N., Wheaton, A., Nield, C., \& Stough, C. (2019). Differentiating the contributions of emotional intelligence and resilience on adolescent male scholastic performance. Personality and Individual Differences, 145, 75-81. https://doi.org/ 10.1016/j.paid.2019.03.023

Duchesne, S., \& Larose, S. (2018). Academic competence and achievement goals: Self-pressure and disruptive behaviors as mediators. Learning and Individual Differences, 68, 41-50. https://doi.org/ 10.1016/j.lindif.2018.09.008

Frazier, P., Gabriel, A., Merians, A., \& Lust, K. (2019). Understanding stress as an impediment to academic performance. Journal of American College Health, 67, 562-570. https://doi.org/10.1080/07448 481.2018.1499649

Fritz, M. S., \& Mackinnon, D. P. (2007). Required sample size to detect the mediated effect. Psychological Science, 18, 233-239. https://doi.org/10.1111/j.14679280.2007.01882.x

Gallagher, D. J. (1990). Extraversion, neuroticism and appraisal of stressful academic events. Personality and Individual Differences, 11, 1053-1057. https:// doi.org/10.1016/0191-8869(90)90133-c

Gatzka, T., \& Hell, B. (2018). Openness and postsecondary academic performance: a meta-analysis of facet-, aspect-, and dimension-level correlations. Journal of Educational Psychology, 110, 355-377. https://doi.org/10.1037/edu0000194

Gustems-Carnicer, J., Calderón, C., \& Calderón-Garrido, D. (2019). Stress, coping strategies and academic achievement in teacher education students. European Journal of Teacher Education, 42, 375-390. https://doi.org/10.1080/02619768.2019.1576629

Hammer, L. B., Grigsby, T. D., \& Woods, S. (2010). The conflicting demands of work, family, and school among students at an urban university. The Journal of Psychology, 132, 220-226. https://doi. org/10.1080/00223989809599161

Hu, L. T., \& Bentler, P. M. (1999). Cutoff criteria for fit indexes in covariance structure analysis: Con- ventional criteria versus new alternatives. Structural Equation Modeling, 6, 1-55. https://doi.org/ 10.1080/10705519909540118

Jöreskog, K. G. (1993). Testing structural equation models. In K. A. Bollen \& J. S. Long (Eds.), Testing structural equation models (pp. 294-316). Sage.

Kassarnig, V., Mones, E., Bjerre-Nielsen, A., Sapiezynski, P., Dreyer Lassen, D., \& Lehmann, S. (2018). Academic performance and behavioral patterns. EPJ Data Science, 7, 10. https://doi.org/10.1140/ epjds/s13688-018-0138-8

Kausar, R. (2010). Perceived stress, academic workloads and use of coping strategies by university students. Journal of Behavioral Sciences, 20, 31-45.

Kilby, C. J., Sherman, K. A., \& Wuthrich, V. (2018). Towards understanding interindividual differences in stressor appraisals: a systematic review. Personality and Individual Differences, 135, 92-100. https://doi.org/10.1016/j.paid.2018.07.001

Kim, S., Fernandez, S., \& Terrier, L. (2017). Procrastination, personality traits, and academic performance: When active and passive procrastination tell a different story. Personality and Individual Differences, 108, 154-157. https://doi.org/10.1016/j. paid.2016.12.021

Laborde, S., \& Allen, M. S. (2016). Comment: Measurement and the interpretation of trait El research. Emotion Review, 8, 342-343. https://doi.org/ 10.1177/1754073916650498

Laborde, S., Dosseville, F., \& Scelles, N. (2010). Trait emotional intelligence and preference for intuition and deliberation: Respective influence on academic performance. Personality and Individual Differences, 49, 784-788. https://doi.org/10.1016/j. paid.2010.06.031

Lazarus, R. S., \& Folkman, S. (1984). Stress, appraisal and coping. Springer.

Mancini, G., Andrei, F., Mazzoni, E., Biolcati, R., Baldaro, B., \& Trombini, E. (2017). Brief report: Trait emotional intelligence, peer nominations, and scholastic achievement in adolescence. Journal of Adolescence, 59, 129-133. https://doi.org/10.1016/j. adolescence.2017.05.020

McCrae, R. R., \& Costa, P. T. (2008). The five-factor theory of personality. In O. P. John, R. W. Robins, \& L. A. Pervin (Eds.), Handbook of personality: Theory and research (3rd ed., pp. 159-181). Guilford Press.

Meyer, J., Fleckenstein, J., Retelsdorf, J., \& Köller, O. (2019). The relationship of personality traits and different measures of domain-specific achievement in upper secondary education. Learning and Individual Differences, 69, 45-59. https://doi.org/ 10.1016/j.lindif.2018.11.005

Miller, J. D., Lynam, D., \& Leukefeld, C. (2003). Examining antisocial behavior through the lens of the five factor model of personality. Aggressive Behavior, 29, 497-514. https://doi.org/10.1002/ab.10064 
Misra, R., \& McKean, M. (2000). College students' academic stress and its relation to their anxiety, time management, and leisure satisfaction. American Journal of Health Studies, 16, 41-51.

Ohtani, K., \& Hisasaka, T. (2018). Beyond intelligence: a meta-analytic review of the relationship among metacognition, intelligence, and academic performance. Metacognition and Learning, 13, 1-34. https://doi.org/10.1007/s11409-018-9183-8

Ost, L. G. (2008). Efficacy of the third wave of behavioral therapies: a systematic review and metaanalysis. Behaviour Research and Therapy, 46, 296321. https://doi.org/10.1016/j.brat.2007.12.005

Park, Y., Seo, D. G., Park, J., Kim, B., \& Choi, J. (2019). The influence of behavioral and emotional characteristics on academic achievement of middle school students: a growth modeling approach. School Psychology International, 40, 433-455. https://doi. org/10.1177/0143034319853010

Perera, H. N. (2016). The role of trait emotional intelligence in academic performance: Theoretical overview and empirical update. The Journal of Psychology, 150, 229-251. https://doi.org/10.1080/0022 3980.2015.1079161

Perera, H. N., \& DiGiacomo, M. (2013). The relationship of trait emotional intelligence with academic performance: a meta-analytic review. Learning and Individual Differences, 28, 20-33. https://doi. org/10.1016/j.lindif.2013.08.002

Plaisant, O., Courtois, R., Réveillère, C., Mendelsohn, G. A. A., John, O. P. P., \& Guertault, J. (2010). Validation par analyse factorielle du Big Five Inventory français (BFI-Fr). Analyse convergente avec le NEO-PI-R [Factor structure and internal reliability of the French Big Five Inventory (BFI-Fr). Convergent and discriminant validation with the NEO-PI-R]. Annales Médico-psychologiques, revue psychiatrique, 168, 97-106. https://doi.org/10.1016/j. amp.2009.09.003

Poropat, A. E. (2009). A meta-analysis of the fivefactor model of personality and academic performance. Psychological Bulletin, 135, 322-338. https:// doi.org/10.1037/a0014996

Rosander, P., Bäckström, M., \& Stenberg, G. (2011). Personality traits and general intelligence as predictors of academic performance: a structural equation modelling approach. Learning and Individual Differences, 21, 590-596. https://doi.org/10.1016/j. lindif.2011.04.004

Saklofske, D. H., Austin, E. J., Mastoras, S. M., Beaton, L., \& Osborne, S. E. (2012). Relationships of personality, affect, emotional intelligence and coping with student stress and academic success: Different patterns of association for stress and success. Learning and Individual Differences, 22, 251-257. https://doi.org/10.1016/j.lindif.2011.02.010

Schmidt, L. I., Sieverding, M., Scheiter, F., \& Obergfell, J. (2013). Predicting and explaining students' stress with the demand-control model: Does neuroticism also matter? Educational Psychology, 35, 449-465. https://doi.org/10.1080/01443410.2013.85 7010

Shaw, S. R., Gomes, P., Polotskaia, A., \& Jankowska, A. M. (2015). The relationship between student health and academic performance: Implications for school psychologists. School Psychology International, 36, 115-134. https://doi.org/10.1177/0143034314565425

Siegling, A. B., Vesely, A. K., Petrides, K. V., \& Saklofske, D. H. (2015). Incremental validity of the Trait Emotional Intelligence Questionnaire-Short Form (TEIQue-SF). Journal of Personality Assessment, 97, 525-535. https://doi.org/10.1080/00223891.2015.101 3219

Stajkovic, A. D., Bandura, A., Locke, E. A., Lee, D., \& Sergent, K. (2018). Test of three conceptual models of influence of the Big Five personality traits and self-efficacy on academic performance: a meta-analytic path-analysis. Personality and Individual Differences, 120, 238-245. https://doi.org/10.1016/j. paid.2017.08.014

Tetzner, J., Becker, M., \& Brandt, N. D. (2020). Personality-achievement associations in adolescenceexamining associations across grade levels and learning environments. Journal of Personality, 88, 356-372. https://doi.org/10.1111/jopy. 12495

Thomas, C. L., Cassady, J. C., \& Heller, M. L. (2017). The influence of emotional intelligence, cognitive test anxiety, and coping strategies on undergraduate academic performance. Learning and Individual Differences, 55, 40-48. https://doi.org/10.1016/j. lindif.2017.03.001

Vedel, A. (2014). The Big Five and tertiary academic performance: a systematic review and meta-analysis. Personality and Individual Differences, 71, 66-76. https://doi.org/10.1016/j.paid.2014.07.011

Wan, T. Y., Chapman, D. W., \& Biggs, D. A. (1992). Academic stress of international students attending U.S. universities. Research in Higher Education, 33, 607-623. https://doi.org/10.1007/bf00973761

Watson, J. C., \& Watson, A. A. (2016). Coping self-efficacy and academic stress among Hispanic firstyear college students: The moderating role of emotional intelligence. Journal of College Counseling, 19, 218-230. https://doi.org/10.1002/jocc. 12045 